\title{
Operaciones de gobernanza urbana en el sur "más vulnerable" de la Ciudad de Buenos Aires. Comuna 8, la producción de nuevas "oportunidades" y viejas desigualdades
}

María-Rosa Privitera-Sixto. Universidad de Buenos Aires, Buenos Aires, Argentina.

RESUMEN | En la discusión sobre procesos de regeneración urbana y el empresarialismo como eje de dicha política, el caso de la Ciudad de Buenos Aires suele ser presentado desde la perspectiva de proyectos que recortan e iluminan áreas centrales, y que generan fragmentos exclusivos de ciudad en su búsqueda por valorizar el espacio local en el mercado global de ciudades. La propuesta de este artículo es focalizar en el análisis de una serie de operaciones de gobernanza urbana articuladas sobre la periferia de la ciudad -que históricamente concentra los indicadores socioeconómicos, habitacionales y educativos "más deficitarios"-, poniendo énfasis en la lógica desde la cual opera el Estado local. En tal contexto se examinan las posibilidades de transformación prometidas en este "retorno" del Estado, observándose el carácter disputado de la producción de "oportunidades".

PALABRAS CLAVE | competitividad urbana, desigualdad social, desarrollo territorial.

ABSTRACT | In the discussion on urban regeneration processes and entrepreneurism as the axis of said policy, the case of the City of Buenos Aires is usually presented from the perspective of projects that cut out and illuminate central areas, generating "exclusive fragments of the city" in its search for valuing the local space in the global market of cities. The proposal of this article is to focus on the analysis of a series of urban governance operations articulated on the periphery of the city - which historically concentrates the "most deficient" socioeconomic, housing and educational indicators -, emphasizing the logic from which operates the local state. In this context, the possibilities of transformation promised in this "return" of the State are investigated, as well as the contested character of the production of "opportunities".

KEYwORDs | urban competitiveness, social inequality, territorial development.

Recibido el 1 de agosto de 2018, aprobado el 30 de septiembre de 2019

E-mail: psmariarosa@gmail.com 


\section{Introducción}

En la discusión sobre los procesos de regeneración urbana y el "empresarialismo" como eje de dicha política, ${ }^{1}$ cuando se examina la Ciudad de Buenos Aires la atención se suele focalizar en proyectos que recortan e iluminan áreas centrales, generando "fragmentos exclusivos de ciudad" en su búsqueda por "maximizar el atractivo del espacio local para el desarrollo capitalista y contribuir a su posicionamiento en el escenario mundial" (Cuenya \& Corral, 2011, p. 26). Asimismo, se señalan los efectos que ello suele tener en el desplazamiento de "los sectores populares y ciertas clases medias" desde "los núcleos centrales de las grandes conurbaciones", cada vez más al servicio del "dinero especulativo financiero-inmobiliario" (Ciccolella, 2012, p. 16). También se ha puesto atención a la expansión heterogénea que dicha modalidad ha tenido hacia el "sur deteriorado" de la ciudad, a través de nuevas burocracias estatales como la Corporación Buenos Aires Sur Sociedad del Estado (CBASSE), ${ }^{2}$ orientada a producir "tejido económico, social y urbano" y así dar solución al "histórico" desequilibrio con respecto a un "norte pujante" de la ciudad (Arqueros \& González Redondo, 2017, p. 12). Por este camino se ha establecido que las llamadas "políticas de equidad" ejecutadas por la CBASSE no resultaron satisfactorias para "todo el sur y sus habitantes", siendo más bien funcionales a la reubicación de "los más vulnerables, que quedaron arrinconados en algunos sectores de ese sur y a los que se los atendió con políticas paliativas, no de emancipación", en tanto se "dio prioridad a la búsqueda de capitales de inversión para que una parte, no todo el sur, se sume al corredor for export, con altas tasas de recuperación del capital de inversión y destinados a reproducir pautas de consumo universales en sectores de medios y altos ingresos" (García, 2013, p. 18).

Pues bien, hace unos años parece efectivamente haber llegado el turno del sur "más vulnerable", el que históricamente concentra los indicadores socioeconómicos y educativos más deficitarios, tanto como un gran número y tamaño de complejos habitacionales, villas y asentamientos, y con ello, el fantasma de la ciudad "informal": la Comuna 8 de la ciudad porteńa, compuesta por los barrios de Villa Lugano, Villa Soldati y Villa Riachuelo. ${ }^{3}$ Es básicamente dicho diagnóstico estatal el que la erige en objeto de una serie de intervenciones tanto materiales como simbólicas, atentas

Planteado por Harvey (1989) como un "nuevo paradigma empresarial” en el sector público, el "empresarialismo urbano" expresa una modalidad de gobernanza, o de regulación política y social que ha reflejado y acompañado los procesos de reestructuración de las economías capitalistas de las últimas décadas, y ha sido adoptado por autoridades locales de tendencias políticas diversas. En estas circunstancias, "la combinación de recursos privados con capacidades gubernamentales sirve para intentar atraer fuentes de financiamiento externo, nuevas inversiones directas, o fuentes de trabajo" (Cuenya \& Corral, 2011, p. 27). La "gobernanza" alude al hecho de que gobernar la ciudad excede al gobierno urbano, e incluye una coalición de fuerzas movilizadas por diversos actores sociales -empresas y promotores inmobiliarios, pero también instituciones educativas y religiosas, partidos políticos, organizaciones sociales, etcétera-, convirtiéndose el gobierno local en "uno más de los múltiples actores y consorcios público-privados" (Cuenya \& Corral, 2011, p. 18).

2 Acerca del cambio en el modelo de desarrollo territorial que expresa la creación del ente autárquico CBASSE respecto a su antecedente institucional, la Subsecretaría de Desarrollo Regional, luego, Desarrollo Sustentable (García, 2013).

3 La división territorial y administrativa de la ciudad en quince comunas responde a normativas sancionadas en 2005 y 2008. 
a la identificación de "oportunidades" de este fragmento y orientadas a decantar su "desarrollo" social, económico y urbanístico (Ministerio de Desarrollo Económico [MDE], 2013, p. 5). Así, la confluencia de vías de acceso, sus recursos "naturales" y la propia infraestructura física y social presentes en ella, son transformados en insumos a la reactivación económica de un territorio "degradado" por la inactividad, la desafección y la subutilización de establecimientos industriales que durante buena parte del siglo xx -modelo de Industrialización por Sustitución de Importaciones (ISI) - fueron eje de la valorización del área. En tal dirección, los legisladores de la ciudad porteńa procedieron a catalogar gran parte de su superficie como "Distrito del Deporte" (2014), con la pretensión de incentivar allí el desarrollo de actividades vinculadas a la industria deportiva, vía exenciones impositivas, por ejemplo. Dicha normativa se teje dentro de la política de "distritos creativos" más general, "una política económica con efectos urbanos” (Socoloff, 2017), que constituye una de las principales intervenciones operadas por la gestión local, bajo el paradigma del "empresarialismo urbano" (Arqueros \& González Redondo, 2017). A diferencia de lo operado en otras zonas, este distrito viene a fortalecer "un perfil industrial tradicional, con industrias que no necesariamente son 'limpias' y que tampoco están incluidas en el repertorio clásico de las actividades 'globales', como ser la fabricación de productos deportivos, la construcción de embarcaciones deportivas y la construcción, mantenimiento y reforma de infraestructura deportiva (Arqueros \& González Redondo, 2017, p. 11). La continuidad de un perfil históricamente fabril de la zona parece dar sustento a la conceptualización de la ciudad de Buenos Aires como expresión de aquel carácter híbrido/mestizo que Ciccolella (2012) describe para las contemporáneas metrópolis latinoamericanas. Finalmente, se determina su conversión en sede de la Villa Olímpica y el Parque Olímpico, que albergaron el espectáculo internacional Juegos Olímpicos de la Juventud 2018 (YOG, por su sigla en inglés).

Este artículo hará entonces foco en el análisis de aquellas y otras intervenciones público-privadas, igualmente llamadas a desencadenar un proceso de reconfiguración económica, urbana y social en "el sur más vulnerable" de la ciudad de Buenos Aires. La hipótesis de trabajo es que se trata de "operaciones de gobernanza urbana”, en las que el Estado local opera desde una lógica empresarial con orientación "emprendedora" (Harvey 1989), en el sentido de crear e identificar oportunidades innovadoras de inversión, capaces de maximizar el atractivo del espacio local y proyectar la imagen de una "confiable ciudad-negocio" (Fiori Arantes, 2000). Nos preguntamos por las transformaciones prometidas y publicitadas por el Estado local en torno a la desigualdad, y si este "retorno" del Estado en la planificación implica una ruptura o es perfectamente funcional a la realización del "capitalismo metropolitano” (Ciccolella, 2012). Ello nos conducirá a observar el carácter disputado de la producción de espacio-temporalidades de "oportunidad".

Resta señalar que el presente escrito constituye un desprendimiento de una investigación más amplia en el campo de las Ciencias Antropológicas, y actualmente en curso. Aquí se trata de avanzar en la descripción y análisis de las intervenciones de gobernanza urbana a que da lugar el diagnóstico de la fragmentación y segregación socioespacial que pesa sobre "el sur más vulnerable". En tanto muchas de las 
intervenciones descritas y analizadas son previas al inicio del proceso de investigación, se ha recurrido a un rastreo y examen de fuentes secundarias referidas a esas intervenciones y su contexto de producción en la esfera pública -leyes, normativas, documentos de circulación interna, comunicados y fuentes periodísticas-, atento a una mirada histórica y teórico-conceptual. Se trató de un trabajo de selección y análisis cauteloso y crítico respecto de las supuestas verdades que estas fuentes "revelarían". Por ello, los pasajes significativos que irán apareciendo a lo largo de la estructura del escrito no deben ser confundidos con una mera transcripción de las fuentes, sino que son resultado de un proceso de codificación de datos que no poseen la naturaleza de una realidad dada, sino que surgen de una reconstrucción realizada a partir del análisis y la elaboración conceptual. Ello remite a la distinción entre referente empírico -base documental para la investigación- y objeto de estudio, "producto del proceso de conocer" (Rockwell, 2009, p. 74) que toma finalmente "la forma de un texto, con narraciones y descripciones organizadas de tal forma que muestren ciertas relaciones de un universo social, que siempre será más complejo" y que "los sujetos tienen la capacidad de transformar" (Rockwell, 2009, p. 75). Al proponer entonces una trama capaz de vincular elementos aparentemente discordantes, lo que se propone es un proceso de configuración narrativa, de simbolización de los acontecimientos, a través del cual conferirles cierta legibilidad (Ricoeur, 1989).

Finalmente, y teniendo en cuenta la sucesión de siglas, entes y acciones que se intenta relacionar en el artículo, a continuacón se incluye una tabla que ordena cronológicamente los procesos mencionados y las agencias estatales asociadas (tabla 1).

\begin{tabular}{|c|c|}
\hline AÑo & INTERVENCIONES Y AGENCIAS ESTATALES \\
\hline $\begin{array}{l}\text { 1978-9 } \\
\text { (Gobierno } \\
\text { de facto) }\end{array}$ & Creación Parque Roca. \\
\hline \begin{tabular}{l|}
1982 \\
(Gobierno \\
de facto)
\end{tabular} & Creación Parque de la Ciudad. \\
\hline 1994 & Sanción Constitución de la Ciudad Autónoma de Buenos Aires. \\
\hline 1996 & Primera elección de representantes del Poder Ejecutivo y Legislativo de la Ciudad. \\
\hline 2000 & Ley 470, creación de la Corporación Buenos Aires Sur Sociedad del Estado (CBASSE). \\
\hline 2003 & $\begin{array}{l}\text { La histórica Comisión Municipal de la Vivienda pasa a denominarse Instituto de Vivienda } \\
\text { de la Ciudad Autónoma de Buenos Aires (IvC), adecuando su normativa a la Constitución y } \\
\text { Leyes de la flamante Ciudad Autónoma de Buenos Aires. }\end{array}$ \\
\hline 2006 & Inauguración del Estadio de Tenis en Parque Roca (sector 3). Gestión CBASSE. \\
\hline 2007 & $\begin{array}{l}\text { Incendio de Villa Cartón y creación del Centro de evacuados de Villa Cartón en Parque } \\
\text { Roca (sector 1). Gestión IVc. }\end{array}$ \\
\hline 2011 & $\begin{array}{l}\text { Creación de la Secretaría de Hábitat e Inclusión (SECHI), como efecto de la restructuración } \\
\text { de funciones del IVc. Dependiente del Ministerio de Desarrollo Económico, este organismo } \\
\text { es el encargado de ejecutar el Proyecto Urbano Integral Comuna Olímpica (PUICO). }\end{array}$ \\
\hline 2012 & Anuncio del Parque de la Ciudad como sede de "Rock in Rio" 2013. \\
\hline \multirow{2}{*}{2013} & $\begin{array}{l}\text { Elección de la Ciudad de Buenos Aires como sede de los Juegos Olímpicos de la Juventud } \\
2018 .\end{array}$ \\
\hline & Primera sanción de lo que será la Ley 5235. \\
\hline
\end{tabular}


(continuación)

\begin{tabular}{|c|c|}
\hline AÑo & INTERVENCIONES Y AGENCIAS ESTATALES \\
\hline 2014 & $\begin{array}{l}\text { Sanción definitiva de la Ley 5235, Promoción de las Actividades de la Producción e Indus- } \\
\text { tria Deportiva en la Ciudad Autónoma de Buenos Aires. Dispone que la Villa Olímpica sea } \\
\text { emplazada en terrenos del Parque de la Ciudad. }\end{array}$ \\
\hline \multirow{3}{*}{2016} & $\begin{array}{l}\text { Ley 5704, desafecta y rezonifica terrenos del Parque de la Ciudad, que asimismo transfiere } \\
\text { a la cBASSE para su posterior venta, así como establece que al menos el } 50 \% \text { de las unidades } \\
\text { habitacionales de la Villa Olímpica sean adjudicadas por el Instituto de la Vivienda (IVC). }\end{array}$ \\
\hline & Inicio Obras Parque Olímpico de la Juventud. \\
\hline & Inauguración del Centro de Transferencia de Cargas (СтС). \\
\hline \multirow[b]{2}{*}{2017} & Inauguración del Terminal Dellepiane (permanece en desuso). \\
\hline & $\begin{array}{l}\text { Creación del Centro de Integración Laboral (CIL) "Villa 20", Ministerio de Modernización } \\
\text { y Subsecretaría de Trabajo de la Ciudad. }\end{array}$ \\
\hline
\end{tabular}

TABLA I Cronología de intervenciones y agencias estatales

FUENTE: ELABORACIÓN PROPIA

\section{La alteridad espacial-temporal de la Comuna 8}

La fuerte concentración de villas, asentamientos, complejos habitacionales y grandes espacios verdes en la comuna señalan, en la mirada del Estado local, su carácter de otredad anómala respecto a "la traza de tipo cuadrícula tradicional del tejido de la Ciudad Autónoma de Buenos Aires", puesto que aquí ella "se encuentra constantemente interrumpida" (Secretaría de Hábitat e Inclusión Social [sEchi], 2015, p. 81). Ahora, ¿hasta dónde dicha concentración y fragmentación responden a una mera postergación en la mirada del Estado? Esta pregunta resulta relevante toda vez que, como se verá más adelante, la sentencia de una "histórica" "ausencia generalizada del Estado" constituye un pilar fundamental de las intervenciones contemporáneas.

En primer lugar, podemos anclar la consolidación de las villas en la Comuna 8 a un proceso histórico que encuentra un hito en la hegemonía del IsI con orientación de bienestar y fortalecimiento del mercando interno. Se trata de un periodo caracterizado por el aumento de la "solvencia popular" que dio lugar a una fuerte expansión metropolitana, proceso en el que la intervención estatal en materia laboral y de producción de infraestructura y servicios -en particular de transporte ferroviario- fue central, pero que, como contrapartida, también generó el asentamiento de la población no solvente para el loteo popular en "villas de emergencia" (Pírez, 1994, p. 22, en Pírez, 2016, pp. 97-98). Ello fue configurando "una ciudad que integraba en forma regular, aunque desigual y segregada, a una parte importante de los sectores populares y que, en el caso de quienes no lograban la solvencia necesaria para los procesos regulares, se les permitían usos clandestinos de los bienes urbanos [suelo] para producir no mercantilmente sus asentamientos" (Pírez, 2016, pp. 98-99). Luego, en el marco de la hegemonía neoliberal, el crecimiento y la consolidación de la población en villas fue efecto de un nuevo rol asumido por el Estado, ahora facilitador o estímulo de las acciones privadas que tienen por protagonistas a los sectores sociales de mayores ingresos (Ballent, 2010). Así, las villas que hoy pueblan la Comuna 8 no son puro legado de la ciudad industrial. Ello se ha visto complejizado en las últimas décadas por la llegada de "la tensión mercantilizadora" a la ciudad autoproducida no mercantilmente, donde se fortalece un mercado 
inmobiliario "informal" (de venta o alquiler) que introduce esos bienes urbanos en relaciones de intercambio monetario, requiriendo para su consumo de cierta solvencia (Cravino, 2006).

Ahora, respecto de los grandes conjuntos habitacionales, ellos fueron mayormente ejecutados durante el último gobierno de facto (1976-1983), ${ }^{4}$ lo que contradice el supuesto de un abandono total del Estado respecto de su viejo rol de constructor directo de vivienda masiva, al punto tal que las políticas militares incluyeron el desarrollo de ideas por aquella época consideradas progresistas, en tanto "superadoras de los aspectos críticos que se atribuían a la ciudad tradicional” (Ballent, 2010, p. 184). En la perspectiva de Ballent, debemos observar en ello un típico rasgo de continuidad con respecto a lo proyectado por gobiernos de la etapa previa a 1976, cuando existía un "reconocimiento político de la necesidad de intervención directa del Estado en la producción y en el mercado de vivienda masiva", y del derecho a la vivienda como derecho social (p. 169). Por el contrario, los grandes conjuntos habitacionales de la dictadura fueron ejecutados descontando la potencial asistencia de las agencias estatales; esto es, fueron liberados a las posibilidades de acción de sus habitantes, haciéndose caso omiso al hecho de que por su envergadura y complejidad formal y organizativa, ellos solo pueden ser mantenidos, administrados y gestionados con un fuerte apoyo público, Además, debe considerarse que muchos de esos habitantes habían accedido a estas vivienda en el marco del Plan de Erradicación de Villas de Emergencia de la Capital Federal y del Gran Buenos Aires $(\text { PEVE })^{5}$ (Ballent, 2010, p. 184).

Finalmente, podemos reseñar que los grandes espacios verdes de escala metropolitana, que también caracterizan la comuna y hoy son fuertemente intervenidos-Parque Indoamericano; Parque de la Ciudad; Parque J. A. Roca-, resultan asimismo parte de otra estrategia urbanística legada por la última dictadura: una estrategia "verde", ligada a su búsqueda por exorcizar la "contaminación" que, en la postal de la Buenos Aires "blanca", los sectores populares representaban al concentrarse en torno a los basurales de la zona (Cosacov, Perelman, Ramos, \& Rodríguez, 2011, p. 77).

Entonces, si la Comuna 8 quedó al margen de aquella grilla "tradicional" de las ciudades argentinas -en comparación con otros países latinoamericanos-que produjo "tejidos urbanos en los cuales los mecanismos de distinción y segregación socioeconómica impuestos por el mercado adoptaron formas relativa y comparativamente lábiles" (Ballent, 2010, p. 173), ello fue consecuencia histórica de lo que Di Virgilio, Perea y Ostuni (2010) definen como una negativa correlación establecida entre la poca importancia que el mercado inmobiliario asignó a la construcción residencial y el fuerte -y complejo- protagonismo de las intervenciones del Estado en el área, en dictadura y en democracia. Asimismo, en tanto a lo largo del siglo xx la cuadrícula fue erigida en "promesa de equidad", y llegó a operar, "cuando supuso la ampliación de la cobertura de los servicios urbanos, como un instrumento de integración social" (Gorelik,

Se suele anclar en este último gobierno de facto el inicio del largo ciclo neoliberal que recién hacia la década de los noventa logró generar un punto de inflexión en cuanto a las tendencias urbanísticas de larga duración en la historia de la Ciudad de Buenos Aires (y su área suburbana) (Gorelik, 2004).

5 Respecto a la ejecución y resultado del PEve diseñado por el último gobierno de facto, que buscaba erradicar la totalidad de las villas de la ciudad, véase Cravino (2006). 
1998, en Ballent, 2010, p. 173), la Comuna 8 revela su alteridad no solo frente a la ciudad porteńa, sino también a la imaginada "excepción” argentina.

Porque, subrayémoslo, la concentración de las tipologías residenciales reseñadas expone la concentración de los indicadores socioeconómicos "más deficitarios" a nivel ciudad. Y ello, según sentencia el diagnóstico sociohabitacional de la Comisión de Vivienda del Consejo Económico y Social de la Ciudad, contribuye "a desarrollar, sostener y reforzar un territorio segregado en relación con el resto de la ciudad” (Rodríguez, Rodríguez, \& Huerta, 2013, p. 55). Un diagnóstico tal estaría en sintonía con los reseñados para las principales metrópolis latinoamericanas, las que, desde mediados de los ańos setenta, vienen siendo objeto de aceleradas transformaciones vinculadas a los procesos de reestructuración económica desplegados a nivel global. Es por tal motivo que han sido conceptualizadas como "agregados de fragmentos" dispersos y segmentados socioeconómicamente, expresión del "agravamiento de una estructura socioeconómica territorial históricamente desigual" (Ciccolella, 2012, p. 10).

\section{Procesos de reconfiguración económica, urbana y social en la comuna "más vulnerable". Entre el "desarrollo" y la "excepción"}

Como fuera anticipado en la introducción, en los últimos años el diagnóstico estatal-porteńo de la fragmentación socioespacial legitima la elección de la Comuna 8 como sede del espectáculo internacional Juegos Olímpicos de la Juventud (Jjooj) 2018. Esto es publicitado por los agentes de Estado local como una "oportunidad" capaz de acelerar no solo el desarrollo económico del fragmento urbano que lo tendrá por sede, sino además su desarrollo social. Tal oportunidad daría concreción a un "modelo de gestión urbana" que busca "romper con el concepto homogeneizador de ciudad, mediante el respeto y potenciamiento de las características históricas, urbanas y sociales de las áreas a intervenir" (SECHI, 2015, p. 16). Según oficializa el Proyecto Urbano Integral Comuna Olímpica (PUICO) producido por la entonces Secretaría de Hábitat e Inclusión Social (SECHI $)^{6}$ en 2015, dicho modelo ha sido replicado de la experiencia desarrollada por la alcaldía de la ciudad de Medellín entre los años 2004 y 2011, denominada "Modelo Medellín de Buen Gobierno y Desarrollo Social Integral", y luego exportado al mercado global de las ciudades como "enfoque de gestión pública y transformación urbana", conocido como "urbanismo social",

[...] un modelo de intervención del territorio que comprende simultáneamente la transformación física, la intervención social, la gestión institucional y la participación comunitaria, buscando promover la equidad territorial, privilegiando la acción del Estado en las zonas periféricas de la ciudad, aquellas con menores índices de

6 La SECHI fue producto de una restructuración de funciones propias del Instituto de la Vivienda operada en 2011, a causa de su "ineficiencia en la implementación de las políticas habitacionales, así como de la constante dificultad para canalizar las demandas por parte de la población afectada” (Zapata, 2013, p. 59). Tal disgregación generó más bien una superposición de funciones entre organismos, tanto como una fragmentación de criterios y objetivos que terminó operando en detrimento de la satisfacción del derecho a la vivienda (L'Huillier \& Ouviña, 2016). 
desarrollo humano y calidad de vida [...] zonas vulnerables de la ciudad, en las que predomina una ausencia generalizada del Estado. (SECHI, 2015, p. 18. El destacado es mío)

Dicha replicación, continúa el documento, se muestra atenta a las recomendaciones de organismos internacionales como onU Hábitat, Metrópolis (Red de Grandes Metrópolis del Mundo) y el Centro Iberoamericano de Desarrollo Estratégico Urbano (CIDEu), los cuales "reconocen en los PUi una forma de abordaje integral y articulada que puede ser replicada por ciudades con problemas similares" (p. 6). Pero también busca "enriquecerlo con su trabajo en las villas de la Ciudad", y de allí que el documento sea presentado como expresión de "la aplicación de aprendizajes que han dado resultado en otros contextos y el diseño e implementación de estrategias complementarias, innovadoras, de alto impacto en el desarrollo de las políticas públicas" (p. 7). Aquí cobra vigencia el análisis desarrollado por Jajamovich (2013; 2016) -enfocado en el caso de grandes proyectos urbanos en la centralidad urbana de Buenos Aires, como Puerto Madero- respecto de la simultaneidad de formas análogas de intervenir y gestionar las ciudades a escala internacional no como efecto mecánico de los procesos de globalización, sino del accionar de múltiples redes de actores y procesos. Tal aproximación nos permite interpretar que: i) la conjuración del espíritu de los organismos internacionales forma parte del proceso de legitimación de la estrategia de intervención urbana; ii) estamos frente a un proceso de movilidad y circulación internacional de políticas y modelos urbanos entre ciudades del sur, más que "desde el 'centro' hacia la 'periferia'"; iii) en estos espejamientos los procesos de aprendizaje son muldireccionales, o por lo menos buscan serlo. ${ }^{7}$

Finalmente, se destaca la definición que el documento presenta del pui como "un modelo de gestión contra la Segregación y Fragmentación Urbana" que busca romper con la imagen de la "ciudad dual" (sic), adscribiendo para ello a "la importancia que asume el Estado como actor privilegiado en la planificación de las mismas [ciudades] y en la elaboración de políticas capaces de disminuir las brechas habitacionales y de oportunidades que han persistido a lo largo de las últimas décadas" (sECHI, 2015, pp. 22-24). A una tal afirmación podríamos contraponer dos reflexiones planteadas por García (2013): i) la densidad de este "sur más vulnerable" fue nutrida por las propias "políticas de equidad" encaradas a través de la CBASSE; ii) desde que la ciudad adquirió su autonomía y su propia normativa (1994), es justamente la promesa del "retorno" del Estado sobre el sur "históricamente postergado", la que viene legitimando las intervenciones económico-urbanas operadas allí, sea como solución a la desigualdad que presenta frente al norte pujante, o como efecto del deseo de posicionar Buenos Aires como espacio de intercambio global.

Podemos entonces preguntarnos si este "retorno" del Estado en la planificación implica una ruptura o es perfectamente funcional a la realización del "capitalismo

7 Será materia de futuros trabajos la indagación sobre la heterogeneidad de actores e interacciones que hacen a la movilidad de esta política urbana. 
metropolitano" (Ciccolella, 2012), ${ }^{8}$ y si en ello realmente se juega algo de la concreción del "Derecho a la Ciudad" (Privitera Sixto, 2018). Esto último, teniendo en cuenta que el documento puico finalmente puntualiza que todas las intervenciones propuestas se estructuran en el deseo de "conseguir el objetivo del Derecho a la Ciudad para todas y todos", entendido como "inclusión social", como "usufructo equitativo de las ciudades dentro de los principios de sustentabilidad, democracia, equidad y justicia social", en el sentido de que "todos los habitantes tengan iguales posibilidades de acceso a los beneficios que ofrece la ciudad y a participar de manera activa y consciente en la toma de decisiones" (sECHI, 2015, p. 20).A la luz de dichos interrogantes, focalizaremos el análisis en las intervenciones urbanas vinculadas a la producción de la Villa Olímpica”-espacio donde se alojarán los contingentes de deportistas competidores- y del Parque Olímpico, requeridos por la realización del evento multideportivo internacional Jjooj 2018,poniéndolas en relación con intervenciones previas y contemporáneas, igualmente concebidas como "oportunidades" llamadas a desencadenar en "el sur más vulnerable", un proceso de reconfiguración económica, urbana y social.

\section{La Villa Olímpica y los terrenos del Parque de la Ciudad. \\ Oportunidad habitacional y laboral}

Con correcciones surgidas de su negociación entre los distintos partidos políticos presentes en la legislatura porteńa, la Ley 5235, sancionada en 2014, dispone que la Villa Olímpica sea emplazada en una porción de terrenos (3,5 ha) del Parque de la Ciudad legado por el último gobierno de facto, como parte de un más amplio proyecto de "renovación estética y funcional del sur de la ciudad" (Tavella, 2018, p. 38). El Parque de la Ciudad, originalmente un parque de diversiones, en tiempos de democracia y a causa de los vaivenes económicos a nivel nacional, y presupuestarios a nivel local, fue perdiendo sus atracciones mecánicas y adquiriendo sobre todo una función de espacio verde de esparcimiento. En este marco de iure, el parque ya había sido seleccionado para comunicar, parafraseando a Fiori Arantes (2000), que la ciudad, y específicamente su área sur, podían dejar de ser un problema y pasar a convertirse en un negocio: su elección como sede del megaevento internacional "Rock in Rio" 2013. Ya se hablaba aquí de "rehabilitar" un sector "degradado del parque", y de una "oportunidad", "porque después 'Rock in Rio' se va y el lugar va a recibir todo el año a los grandes shows en un lugar para 100.000 personas, con 10.000 parkings, 8000 lugares para bicicletas y con el Metrobús pasando por ahí". Con ello se contribuiría no solo a "poner en valor" un parque "que está abandonado desde hace 30 años", sino a lograr "que el sur de la ciudad exista" (Jefe de Gobierno en La Nación, 4/06/2012). No está de más señalar que justamente, este "olvido" había garantizado unos años antes (2007) que allí se instalara una de las sedes del "provisorio" e improvisado Centro de Evacuados para habitantes de una de las villas

Refiere a un tipo de capitalismo "que se realiza a través del territorio urbano-metropolitano", donde "el capital privado aparece como ordenador territorial preponderante, basándose en los múltiples recursos o ventajas competitivas de cada porción de territorio, extrayendo las plusvalías más cuantiosas precisamente de las singularidades y especificidades que hacen de cada territorio el lugar óptimo para cada tipo de producción" (Ciccolella, 2012, p. 16). 
de la zona, cuando los "vecinos" de la ciudad "formal" se resistían a albergar su relocalización. ${ }^{?}$

Pues bien, en 2014, la elección de ese mismo parque para el emplazamiento de la Villa Olímpica fue respaldada por los nuevos funcionarios -continuadores de la gestión previa-, haciendo referencia a la misma imagen de "un área relegada de la Ciudad [...] tanto en términos económicos como sociales" que, sin embargo, "posee un importante potencial a escala metropolitana y regional gracias a sus vías de acceso desde distintas autopistas" y a distintos medios de transporte. Otra nueva "oportunidad" que

dejará un legado tangible asociado a todas las obras de infraestructura y de mejoras en las que se desarrollarán las competencias. Y a la vez, un legado intangible difundido a través de los programas culturales, deportivos y educativos basados en el olimpismo y sus valores, para que sean un catalizador para el desarrollo urbano y social de la Ciudad. (Jefe de Gobierno, Larreta, 24/07/2017)

Respecto al "legado tangible" de la potencia creadora, la Ley 5704, sancionada en 2016, deja establecido que al menos el 50\% de las unidades habitacionales (departamentos de 1, 2 y 3 ambientes) sean adjudicadas por intermedio del Instituto de la Vivienda de Buenos Aires (IVC) "o el organismo que en el futuro lo reemplace", sobre la base de "operatorias de crédito bancarias a tasas preferenciales en entidades públicas de la Ciudad". Los beneficiarios serían "vecinos que acrediten al menos cinco (5) años de residencia efectiva en la Comuna 8, siempre y cuando cumplan con los requisitos establecidos para el acceso de dichas viviendas, caso contrario se cumplirá dicho porcentaje dando prioridad a vecinos que habiten las restantes comunas del sur de la Ciudad" (art. 11). Por otro lado, y en el contexto de aquellas otras obras planteadas en el PUico y la Ley 5704, destinadas a "radicar" las otras "villas" que concentra la comuna, la nueva urbanización Villa Olímpica también prometía, en palabras del ministro de Desarrollo Urbano y Transporte,

llevar ciudad donde no la hay. [...] Vamos a construir un barrio con mixtura de vivienda de clase media y vivienda social. Habrá un parque temático, equipamiento deportivo, instituciones educativas y un hospital. Vivirán 30 mil personas. Las manzanas serán de 90 x 90, como las del norte de la ciudad, con edificios de 7 pisos de altura máxima. (Clarín, 4/09/2016).

Pues bien, según argumentaban los legisladores del oficialismo porteño en los fundamentos del despacho conjunto de las comisiones de Obras y Servicios Públicos y de Presupuesto de la legislatura local, para concretar el doble objetivo del Jjooj y del Legado de Revitalización Urbana, "sumada la obligación de encuadrar los proyectos dentro del plazo crítico hasta la fecha de los Juegos", era necesario recurrir a financiamiento (Noticias Urbanas, 16/05/2016). Dicho discurso legitimaba en la legislatura porteña - por 32 votos a favor, 13 en contra y 12 abstenciones- la toma de deuda pública por parte del Ejecutivo porteño, a través de su Ministerio de Hacienda,

9 Para un análisis más detallado del "conflicto" en torno a la relocalización de la Villa Cartón, véase Palombi (2013) y Sarmiento (2011). 
por un monto máximo de hasta dólares estadounidenses ciento sesenta millones (US\$160.000.000) o su equivalente en pesos, otra u otras monedas [...] en el mercado local y/o internacional, a uno o más empréstitos con la Corporación Andina de Fomento y/u otros Organismos Multilaterales de Crédito, Bancos de Desarrollo, Instituciones Financieras de Fomento de las Exportaciones y/o cualquier otra institución financiera local o internacional, los cuales tendrán un plazo mínimo de amortización de tres (3) ańos; y/o a emitir títulos de deuda en el mercado local y/o en el mercado internacional, los cuales tendrán un plazo mínimo de amortización de un (1) año.

Esto merece subrayarse, porque aquel actor que demanda de forma crítica el financiamiento es el partido que gobierna la ciudad desde hace diez años. Aquí se constata que, al igual que en otras ciudades anfitrionas de espectáculos deportivos internacionales, el sello de los Juegos Olímpico ha pasado a "representar una oportunidad única de realizar operaciones urbanas jamás posibles en un periodo tan corto de tiempo y en condiciones tan favorables en términos políticos y sociales" (Cortes de Lira, 2012, p. 15).

Luego, la mencionada Ley 5704 terminó de "reconfigurar" las restantes 96 hectáreas del Parque de la Ciudad circundantes a la Villa Olímpica, las cuales fueron rezonificadas para generarles una nueva productividad. Si bien la mayoría de ellas (76 ha) prometen ser destinadas a "uso público" (20 a calles, veredas y bulevares; 7 a servicios públicos de salud y educación; 49 a un nuevo parque metropolitano), otras tantas (20 ha) son "desafectadas del dominio público", declaradas como "innecesarias para la gestión del Gobierno de la Ciudad de Buenos Aires" y transferidas a la CBASSE para su posterior enajenación. A la hora de legitimar dicha operación mercantil, nuevamente aparecen en conexión los argumentos de la mixtura de usos del suelo -vivienda, oficinas, comercios- como la promesa de urbanización de villas de la zona, en tanto con dicha venta se generarían las partidas de capital necesarias para la concreción de las tantas veces prometida urbanización de la Villa 20. Y junto con ello, la realización de otras tantas obras requeridas en la comuna: hidráulicas, pluviales, de mejora del espacio y del transporte público, incluidas las referidas al inconcluso hospital de la comuna, cuyo proyecto original data del ańo 1986. Asimismo se deja establecido que, en el caso de que los inmuebles sean destinados a vivienda, el comprador de estos predios deberá garantizar que al menos un $10 \%$ de los mismos sea comercializado vía contratos de leasing (alquiler con opción de compra) a vecinos de la Comuna 8 .

Llegados a este punto, podemos preguntarnos si multiplicar el número de unidades habitacionales en la periférica Comuna 8 garantizará la concreción del derecho a la vivienda, cuando lo que no se está resolviendo a nivel ciudad es la regulación del mercado de los alquileres, ni el tema de la vivienda "ociosa”. Al contrario, todo indica que no se están desarrollando mecanismos para que la ciudad toda garantice la concreción del derecho de sus habitantes a la vivienda digna. Concluimos, entonces, que aun cuando prometen mejorar el bienestar de la población, estas obras no parecen venir a garantizar una solución habitacional para los sectores "más vulnerables". Tal inferencia se reviste aún de mayor solidez cuando 
tenemos en cuenta que la explícita búsqueda de impactar en la "revalorización" del metro cuadrado de la zona, en tanto indicador de desigualdad respecto al resto de la ciudad (sECHI, 2015, p. 84), viene a reforzar los procesos de desigualdad no ya entre norte y sur de la ciudad, sino entre quienes tienen capacidad y habilidad de acceso a un crédito y, por ende, a una vivienda digna, y quienes no cuentan con tales posibilidades. Tampoco a resolver el problema del hacinamiento, ya que los parcelamientos de las villas y la entrega de títulos de propiedad a sus habitantes se hacen aun cuando no se cumplan normas mínimas de una vivienda saludable ni segura, legalizándose así la precariedad y el ingreso de nuevas tierras al mercado inmobiliario formal (Busti, 2016). En tiempos de democracia, y como han planteado otros autores (Cortes de Lira 2012; Vainer, 2011), el argumento de un calendario limitado e inalterable propio a un evento internacional, más bien se erige en justificativo de "flexibilización" de la legislación urbanística, y de supresión de la participación popular y de espacios de producción del "interés común", cuya temporalidad atentaría contra la urgencia del calendario. Las promesas de embellecimiento y revitalización de las áreas "relegadas" son, más bien, el anzuelo para conquistar la aprobación y el consenso, sino de la población, por lo menos de los legisladores de partidos opositores. Como se ve, el Estado puede "recuperar" cierto rol planificador, lo que no quiere decir que "recupere" una lógica desmercantilizadora (Herzer \& Pírez, 1993).

Por último, el Ministerio de Modernización, junto con la Subsecretaría de Trabajo de la Ciudad, dispusieron la creación de un Centro de Integración Laboral (CIL) y su emplazamiento al interior de una villa aledaña a la Villa Olímpica, para que fueran sus habitantes los que cubrieran la demanda de trabajo generada por la realización de las obras planificadas. Se intentaba así, por una lado, armonizar las "oportunidades" abiertas a las empresas, asumiendo costos y riesgos que los poseedores del capital no pueden o desean correr; y por otra, "igualar las oportunidades" de la población local, aspecto que se sumaba a la oferta de créditos hipotecarios "blandos". El cIL oficiaría como intermediario entre las empresas que requirieran personal y la población local, y ofrecería cursos de capacitación y orientación laboral. En este sentido, se reconoce que "en un principio, la demanda de trabajadores surgirá de las constructoras, pero más adelante se sumarán las empresas de los diferentes rubros necesarios para organizar el evento", llegando a estimarse "que, además de las 3000 personas que trabajarán en la obra de la Villa Olímpica, se va a emplear a otras 5000 para limpieza, gastronomía y transporte, entre otras tareas" (Clarín, 16/06/2016).

Vale también aquí reflexionar acerca de las "oportunidades" que las intervenciones público-privadas están ofreciendo para la población local, la cual en conjunto concentra los mayores Índices de Vulnerabilidad Educativa (IVE) ("sobreedad", "repitencia", "abandono") tanto a nivel primario (0,249 frente a un promedio ciudad de 0,188$)$, como a nivel secundario $(0,318)$. Se trata de una situación que se ve reflejado en el nivel de escolaridad alcanzado por la población mayor de 25 años, en tanto también concentra el mayor porcentaje de población que no terminó el nivel primario $(9,8 \%)$, mientras más de la mitad no logró finalizar el secundario (53,5\%, porcentaje equivalente al 27\% a nivel ciudad) (sECHI, 2015, p. 84). Más 
que oportunidades para la población local, se identifica para el sector "privado" una gran reserva de mano de obra no calificada y barata.

El "Parque Olímpico" y las intervenciones sobre el Polideportivo Parque Roca. Oportunidad educativa y laboral

Al igual que el Parque de la Ciudad, el Polideportivo Parque Roca (120 ha) forma parte de aquella estrategia urbanística legada por el último gobierno de facto en su búsqueda por exorcizar la "contaminación" que los sectores populares concentrados en torno a los basurales de la zona representaban en la postal de la Buenos Aires "blanca" (Cosacov et al., 2011, p. 77). Para ello fue equipado con infraestructura deportiva que operaría como "medio formativo y educativo" (Menazzi, 2018 , p. 20). Sin embargo, al igual que en el caso del Parque de la Ciudad, la falta de mantenimiento necesario fue haciendo primar un uso más de esparcimiento de los habitantes de la zona que de oferta deportiva, dadas sus extensas dimensiones de espacio verde. Luego, los Jjooj 2018 también fueron presentados como una oportunidad estratégica de renovación, vía conversión de un sector del parque en una de las tres sedes en que se disputaría la competencia. Tal transformación ha sido considerada como "la inversión [pública] en infraestructura deportiva más grande de la historia de nuestro país [60 millones de dólares]" (Ministro de Desarrollo Urbano y Transporte, 20/09/2016).

Esta reconversión de un sector del parque en el nuevo "parque interdisciplinario de alto rendimiento deportivo" (30 ha, referenciadas por los vecinos de la zona como "poli 2") le significó perder lo que le quedaba de esparcimiento público. Ahora bien, el Ejecutivo porteño sostiene que al finalizar los Jjooj, las nuevas instalaciones (piletas, canchas, pistas, etcétera) serán puestas a disposición del Centro de Alto Rendimiento Deportivo (CENARD) para usufructo de "los vecinos y atletas argentinos", garantizándose así que no quede "como en alguna otra ciudad, una Villa Olímpica fantasma” (Larreta, 20/09/2016). Pero en tanto el CENARD ya dispone de instalaciones en el norte pujante de la ciudad (11 ha), se ha generado el rumor, respaldado en declaraciones del propio presidente del Comité Olímpico Argentino (La Nación, 1/10/2016), de que el Gobierno de la Ciudad de Buenos Aires (GCBA) intentará gestionar una permuta entre ambos terrenos.

Entonces, teniendo en cuenta que desde hace algunos ańos el GCBA viene intentando posicionar la ciudad como referente regional del deporte (Vicejefe de Gobierno, Santilli, en Noticias Urbanas, 3/09/2017), la incorporación de "infraestructura de vanguardia y de alto rendimiento" que la intervención supone (Ministro Desarrollo Urbano y Transporte, en $L P O$ 1/09/2016) representa una típica operación de "empresarialismo urbano". Esto es, una acción centrada en "mejorar" la capacidad competitiva de la ciudad en "la división espacial del consumo", a partir de la producción de una imagen atractiva de este fragmento de ciudad, como "lugar innovador, interesante, creativo y seguro para visitarlo o en el que vivir, jugar y consumir" (Harvey, 1989, p. 377). Ahora, si el rumor termina siendo cierto, las intervenciones sobre este fragmento urbano no buscarían más que decantar atractivos negocios inmobiliarios en un área que posee uno de los metros cuadrados más 
caros de la ciudad, no haciendo con ello más que reproducir las desigualdades entre su norte y su sur.

Cabe destacar que con "la misión de promover el desarrollo de la zona sur de la ciudad”, el Parque Roca ya venía siendo objeto de otras intervenciones gestionadas por la СBASSE, vinculadas a la creación de "un centro deportivo de alto nivel" en articulación con inversores privados, los que ya en 2006 se mostraban "interesados en levantar un estadio de cemento, que podría utilizarse para tenis, otros deportes y también para recitales" (Rodríguez, presidente de la CBASSE, en Clarín, 26/01/2006). La "oportunidad" llegaría con el espectáculo deportivo internacional Copa Davis y sus semifinales 2006, ocasión para la cual en menos de tres meses se construyó un estadio de tenis de escala metropolitana, cuyas dimensiones lo convirtieron en uno de los más importantes de Sudamérica (14.500 espectadores). Si bien la obra fue considerada por la CBASSE como "de alto impacto positivo para la zona y para el mundo del deporte”, ella también significó la inhabilitación del libre acceso a esa área del parque ("poli 3"). Tal situación fue denunciada por sectores opositores y organizaciones sociales que cuestionaban tanto la elección de las "prioridades" en un contexto de graves carencias habitacionales, como el discrecional uso de los recursos que comprometía la Corporación, llegando algunos a demandar su inconstitucionalidad "por utilizar los bienes y partidas transferidas por el Ejecutivo sin ningún tipo de revisión por parte de la Legislatura” (García, 2013, p. 16).

Finalmente, una década más tarde, un último sector del parque sería sustraído al acceso público ("poli 1", 37 ha), con el objeto de albergar allí el primer Centro de Transferencia de Cargas (стс) de la ciudad, destinado a concentrar las operaciones de carga y descarga de empresas de transporte que operaban en distintos puntos de la ciudad. Se trata de un sector del parque que también fue la primera sede del "provisorio" campamento de evacuados de la ex villa cartón, improvisado por el ejecutivo porteño el verano de 2007, tras el incendio que consumiera las viviendas de 460 familias hacinadas bajo la autopista que el último gobierno de facto también legó a la zona, aunque sin terminar. Tras el desalojo del "centro de evacuados" -por conminación del Poder Judicial a garantizar "estándares mínimos en materia de seguridad, salubridad, higiene, accesibilidad, transporte y alimentación, entre otros”-, este sector del parque fue elegido para albergar el стC.

El CTC prometía reordenar la circulación de entre 3.500 y 5.000 camiones, liberar 100.000 metros cuadrados de avenidas y calles comunes, mejorando con ello "la calidad de vida en los barrios residenciales con menos ruido y menos contaminación", y específicamente "revalorizar la Comuna 8 con desarrollos comerciales y oportunidades de trabajo" (Ministro Desarrollo Económico, 9/11/2015). Según el actual presidente de la Nación, presente en la inauguración, se trataba de otra obra "innovadora", "de nivel mundial, que existe en muy pocas ciudades del mundo", que "constituye un modelo operativo de referencia para las principales ciudades de América Latina”, y que vuelve "a demostrarnos [a] los argentinos qué somos capaces de hacer cuando nos proponemos trabajar en conjunto, sector público y sector privado. Cuando nos proponemos pensar, diseñar, programar y comprometernos, somos capaces de hacer cosas de calidad internacional" (Jefe de Gobierno, 8/09/2016). 
Nuevamente, observamos el modo en que las prácticas de empresarialismo urbano transforman este fragmento de ciudad en insumo a la proyección de una imagen de ciudad competitiva a escala global (Fiori Arantes, 2000). En esta forma de hacer ciudad, aquello que es celebrado por el "sector público" como parte de "un trabajo conjunto", no supone otra cosa que operar a favor de los intereses del sector privado, nucleado aquí en la Federación Argentina de Entidades Empresarias del Autotransporte de Cargas, diseńadora e impulsora del proyecto de la СтC que define otorgar(se) "incentivos" bajo la forma de beneficios tributarios (exenciones; diferimientos) y créditos baratos a las empresas que decidan trasladarse allí. Esto, aun cuando la obra ya supone, por sí misma, una reducción en los costos de la circulación de las mercancías, toda vez que el proyecto habilita la realización de maniobras de carga y descarga, redistribución, almacenamiento y servicios vinculados a la logística del transporte de mercadería, "las 24 horas durante los 365 días del año". En todo caso, la mención de la стс resulta relevante en tanto expone de modo explícito el valor que para el partido de gobierno tiene, tanto a nivel nacional como local, ser "promotores" del vínculo entre urbanización y capitalismo (Harvey, 1989; 2003a), en el sentido de generar la infraestructura elemental a la circulación de mercancías (Ciccolella, 2012).Y porque en esa articulación, el sector privado -entidades y cámaras empresariales- se apropia de las imágenes de un sur carente de vitalidad, y por ende riesgoso, puestas en circulación por las propias narrativas "redentoras" del Estado, para entonces demandar incentivos que vuelvan atractiva la zona, y así disputar rentabilidad.

En este sentido, observamos que las articulaciones entre "sector público" y "sector privado" tampoco están dadas, ni son tan cordiales como los "competentes" administradores pretenden, puesto que se ven obligados a negociar y confrontar con aquellos que impugnan la urgencia y las narrativas legitimadoras de las intervenciones físicas y sociales operadas sobre "el sur", en su búsqueda por la realización de plusvalía. Ello se expresa más claramente en la situación de la nueva Terminal de Ómnibus de media y larga distancia (Dellepiane). Aunque emplazada en los márgenes de la Comuna 8, está conectada físicamente a las obras de la Villa Olímpica y del Parque Olímpico, vía aquella red de autopistas planificada por el último gobierno de facto y materializada por gobiernos democráticos; y también conectada conceptualmente, al estar destinada a "construir tejido económico, social y urbano en el sur de la ciudad".

Para la producción de dicho equipamiento, que además de "descomprimir el tránsito de micros desde el centro porteño" promete "crear un nuevo nodo en el sur de la ciudad", la CBASSE, en conformidad con la legislatura porteña y el Ejecutivo nacional, cedió a la empresa Terminales Terrestres Argentinas s.A. el usufructo a 18 años de 4 hectáreas valoradas por su "ubicación estratégica”, en tanto allí confluye una red de cinco autopistas (ministro de Modernización, Innovación y Tecnología en La Nación, 16/03/2017). Ahora, luego de varios ańos y una inversión privada de 30 millones de dólares, las tensiones que permean el vínculo entre distintas fracciones del sector público y del privado sabotean su usufructo. Así, el sector nucleado en la Cámara de Empresas de Buses de Larga Distancia (CELADI) denunciaba ya desde su inauguración, en marzo 2017, lo obsoleto de la "moderna" terminal, tanto como los problemas operativos, vinculados al alto costo que para empresas y usuarios supondría su 
puesta en funcionamiento. Además, le recriminaba al sector público poner en marcha un proyecto que solo beneficiaba al "operador privado", diseñador e impulsor de la iniciativa:

nosotros no tenemos ningún apuro a que funcione porque no hay demanda de pasajeros en la zona [...] es una iniciativa privada que va contra la tendencia del futuro, que es comprar pasajes vía internet o por teléfono. La empresa puede poner 500 boleterías, pero van a generar costos descomunales que después van a terminar pagando las empresas [...] [Además] Para llegar, el usuario perdería más de una hora de viaje y podría pagar dos peajes [...] primero hay que garantizar el acceso a los pasajeros. Es una zona bastante insegura y sólo se ha modificado un puñado de líneas de colectivo, tienen que llegar más. También la promesa de que llegue el subte a la zona, que según nos dicen desde el Gobierno, no se va a concretar por lo menos en 10 ańos. Además, cerca está el polo logístico de camiones por lo que hemos pedido un estudio de impacto de movimiento en la zona, porque podría volverse intransitable. (CELADI, en Urgente 24, 16/03/2017. El destacado es mío)

A partir de esta disputa, es posible observar y sintetizar la continuidad de formas en que el área ha sido y sigue siendo representada. El punto de continuidad es un mecanismo de urbanización neoliberal que Theodore, Peck y Brenner (2009) categorizaron como de "representación de la ciudad", cuyo "momento de destrucción" implica la articulación de "discursos performativos sobre desorden urbano, clases peligrosas y declinación de la economía"; y que en su "momento de creación" articula "discursos empresariales y representaciones enfocadas en la revitalización y rejuvenecimiento de las ciudades y la reinversión en ellas” (p. 9). Ahora bien, como expone la disputa, estos momentos de destrucción y creación de la urbanización neoliberal no se suceden de forma lineal, sino que el diagnóstico estatal es reapropiado y manipulado por sectores que, al contrario de lo que proyectan los discursos de los funcionarios, no son homogéneos ni armónicos. De hecho, apuntan a disputar la tempoespacialidad de la "oportunidad" y, por este camino, definir quién es legítimo productor de la revitalización y rejuvenecimiento de las ciudades y, por ende, propietario de la riqueza socialmente producida.

\section{Reflexiones finales}

El objetivo de este trabajo fue analizar el proceso de reconfiguración urbana que el GCBA está intentando operar sobre un área "históricamente relegada" de la ciudad, la Comuna 8, con miras a "revertir la desigualdad existente". Ello nos condujo a observar la presencia de típicas operaciones de empresarialismo urbano similares a las que acontecen en áreas centrales de la ciudad porteńa, donde los agentes de Estado local señalan estar produciendo mercado (del suelo, comercial, industrial) allí donde 'no existía'. A lo largo de este proceso, van poniendo los recursos públicos al servicio de apalancar los emprendimientos privados (Soccolof, 2017), para lo cual también resulta clave modelar ciertas "representaciones de la ciudad" (Theodore, Peck, \& Brenner 2009, p. 9) y la imagen de "administradores competentes". Esto es, capaces de conjugar la realización de "oportunidades" para las empresas al asumir costos y riesgos que los poseedores del capital no pueden o desean correr; y para 
la población local, generando puestos de trabajo y oferta de créditos hipotecarios "blandos".

Entonces, aun cuando el sector privado ofrezca a la población local ser mano de obra en la producción de plusvalía, o al sector público le prometa facilidades financieras para acceder a la nueva infraestructura habitacional, ello no supone la concreción de su derecho a la ciudad. Este es "mucho más que un derecho de acceso individual o colectivo a los recursos que esta almacena o protege" (Harvey 2012, p. 20) o "a lo que los especuladores de la propiedad y los funcionarios estatales han decidido, sino el derecho activo a hacer una ciudad diferente, a adecuarla un poco más a nuestros anhelos y a rehacernos también nosotros de acuerdo a una imagen diferente" (Harvey, 2003b, p. 939).

Evidentemente, poco importa si todo ello redunda en la declaración de obsolescencia de las grandes obras de que viene siendo objeto la comuna, o si la obsolescencia responde a otros factores, como la existencia del Parque Olímpico. Ello, en primer lugar, porque es justamente en la "revitalización" de lo obsoleto donde las alianzas público-privadas encontrarán nuevas "oportunidades" de desarrollo, al absorberse los riesgos "espanta" inversiones con recursos público-estatales. Y, luego, porque de hecho tal retorno estatal viene siendo conjurado por los gobernantes de la ciudad porteña desde que ella adquirió su autonomía institucional (1990), por no ahondar en el retorno estatal que quiso significar el proyecto urbano, físico y social de la última dictadura en el área, mostrando lo elemental que resulta la gobernanza de este fragmento de ciudad. Ello mismo garantiza que la ciudad más rica del país pueda ser modelada bajo el prisma de la "excepción" (Vainer, 2011), en la que la urgencia del "retorno" impone la necesidad de un actuar veloz y competente de los administradores urbanos en el "aprovechamiento" de las oportunidades, en detrimento de la discusión pública de las prioridades que es necesario atender.

Se concluye, entonces, que las formas de intervención sobre este fragmento de ciudad están en sintonía con los procesos de urbanización del neoliberalismo tramados en distintas regiones del mundo capitalista, que han transformado las ciudades en "metas estratégicas y terrenos de prueba para una cada vez más amplia gama de experimentos de políticas neoliberales, innovaciones institucionales y proyectos políticos [...] incubadoras para la reproducción del neoliberalismo como régimen institucional 'viviente' y en nodos generadores al interior de él" (Theodore, Peck, \& Brenner, 2009, pp. 10-11). Asimismo, que en el "aprovechamiento estratégico" del nuevo evento internacional Jjooj 2018 no solo se juega la producción de oportunidades en términos productivos, sino la conjuración de una sociedad erguida en torno a "una moral de deportistas de alto rendimiento", por la cual sus miembros se sienten compelidos a jugar y ganar, a merecer el éxito tanto como el fracaso (Dubet, 2014 , p. 82). Se trata de la oportunidad de reproducir y legitimar un paradigma que no cuestiona las desigualdades sociales, sino que ofrece a cada individuo la promesa de que es posible aspirar a todas las posiciones sociales - por más desiguales que estas sean-, de acuerdo con una lógica meritocrática en función de la cual el Estado debe limitarse a garantizar la igualdad de oportunidades (Dubet, 2014). 


\section{Referencias bibliográficas}

Arqueros, S. \& Gonzales Redondo, C. (2017). La política de distritos del sur de Buenos Aires: una mirada en perspectiva. Quid 16(6), 7-30. https://dialnet.unirioja.es/servlet/ articulo? codigo $=6055074$

Ballent, A. (2010). Los nuevos mosaicos: políticas de vivienda y cultura del habitar, 1976-2002. En Torrado, S. (ed.), El costo social del ajuste (Argentina, 1976-2002) (pp. 169-213) Buenos Aires: Edhasa.

Busti, S. (2016). El plan maestro de la Comuna 8 (Distrito del deporte). Renovando el Sur ¿Por qué y para qué? http://www.ateneacentro.com.ar/el-plan-maestro-de-la-comuna8-distrito-del-deporte.

Ciccolella, P. (2012). Revisitando la metrópolis latinoamericana más allá de la globalización. Revista Iberoamericana de Urbanismo, (8), 9-21. https://upcommons.upc.edu/ bitstream/handle/2099/13012/08_01_Ciccolella.pdf

Cortés de Lira, A. (2012). Los megaeventos y sus consecuencias urbanas. Posibles perspectivas hacia las futuras experiencias brasileñas. Arxiu d'Etnografia de Catalunya, 12, 9-32. https://doi. org/10.17345/aec12.9-32

Cosacov, N., Perelman, M., Ramos, J., \& Rodríguez, F. (2011). Villa Soldati. Documentos de Trabajo 56. Buenos Aires: Instituto de Investigaciones Gino Germani (IIGG), Facultad de Ciencias Sociales (FSC), Universidad de Buenos Aires (UBA).

Cravino, M. (2006). Las villas de la ciudad. Los Polvorines: Universidad Nacional de General Sarmiento (UNGS).

Cuenya, B. \& Corral, M. (2011). Empresarialismo, economía del suelo y grandes proyectos urbanos: El modelo de Puerto Madero en Buenos Aires. EURE, 37(111), 25-45. http:// dx.doi.org/10.4067/S0250-71612011000200002

Di Virgilio, M., A., Perea, C., \& Ostuni, F. (2010). La ciudad al sur de la ciudad: historia socio-urbana de los barrios Villa Lugano y Villa Riachuelo. Cuadernos de Vivienda y Urbanismo,3(6), 246-261. https://bit.ly/2lMHRu8

Diario Clarín (2006, 26 de enero). https:/www.clarin.com/ediciones-anteriores/parque-rocaestadio-propio_0_SksfQNLJRYe.html

Diario La Nación (2012, junio 4). https://www.lanacion.com.ar/1454562-rock-in-rio-llega-a-laargentina

Diario La Nación (2016, enero 10). https://www.lanacion.com.ar/1943176-el-futuro-delcenard-en-nunez-una-incognita

Diario La Nación (2017, marzo 16). https://www.lanacion.com.ar/1993954-dellepiane-lanueva-terminal-de-omnibus-esta-lista-para-ser-una-alternativa-a-retiro

Dubet, F. (2014). Repensar la Justicia Social. Contra el mito de la igualdad de oportunidades. Buenos Aires: Siglo XxI.

Fiori Arantes, O. (2000). Uma estratégia fatal: a cultura nas novas gestóes urbanas. En O. Arantes, C. Vainer, \& E. Maricato, A cidade do pensamento único: desmanchando consensos (pp. 11-74). Petrópolis: Vozes.

García, I. (2013). Políticas territoriales en la Zona Sur de la Ciudad Autónoma de Buenos Aires. Análisis comparativo. Acta Académica. X Jornadas de Sociología, 1 al 7 de julio de 2013, Facultad de Ciencias Sociales (FCS), Universidad de Buenos Aires (UBA). http://cdsa. aacademica.org/000-038/369 
Gorelik, A. (2004). Miradas sobre Buenos Aires. Buenos Aires: Siglo XXI.

Harvey, D. (1989). From managerialism to entrepreneurialism: the transformation in urban governance in late capitalism. Geografiska Annaler, 71(1), 3-17. https://doi.org/10.10 80/04353684.1989.11879583

Harvey, D. (2003a). 'Accumulation by dispossession'. The new imperialism. New York: Oxford University Press.

Harvey, D. (2003b). The right to the city. International Journal of Urban and Regional Research, 27(4), 939-941. https://doi.org/10.1111/j.0309-1317.2003.00492.x

Harvey, D. (2012). Ciudades rebeldes. Madrid: Akal.

Herzer, H. \& Pírez, P. (1993). Gestión urbana en ciudades intermedias de América Latina. Nairobi: Centro de las Naciones Unidas para los Asentamientos Humanos (CNUA).

Jajamovich, G. (2013). Miradas sobre intercambios internacionales y circulación internacional de ideas urbanas. Andamios, Revista de investigación social, 10(22), 91-112. http:// dx.doi.org/10.29092/uacm.v10i22.268

Jajamovich, G. (2016). Puerto Madero 'en movimiento': movilidad de políticas y modelos urbanos en América Latina (1999-2012). INVI (Facultad de Arquitectura y Urbanismo de la Universidad de Chile), 31(87), 59-84. https://revistas.uchile.cl/index.php/INVI/ article/view/43742

Jaramillo, S. (1988). Crisis de los medios de consumo colectivo urbano y capitalismo periférico. En L. M. Cuervo, S. Jaramillo, J. I. González, \& F. Rojas, Economía política de los servicios públicos. Una visión alternativa, Bogotá: Centro Iberoamericano de Editores Paulinos (CIDEP).

Larreta, H. (2016, septiembre 20). http://www.buenosaires.gob.ar/noticias/rodriguez-larretarecorrio-la-futura-villa-olimpica-es-la-obra-mas-grande-que-se-esta.htlm

Larreta, H. (2017, julio 24). http://www.buenosaires.gob.ar/noticias/la-villa-olimpica-unaobra-que-no-detiene-su-marcha.htlm

Ley 5235/2014. Legislatura de la Ciudad de Buenos Aires. Promoción de las Actividades de la Producción e Industria Deportiva en la Ciudad Autónoma de Buenos Aires. Leyes-ar. com. https://bit.ly/2kHM2Y0

Ley 5704/2016. Legislatura de la Ciudad de Buenos Aires. Modificación al Código de Planeamiento Urbano de la Ciudad de Buenos Aires. http://www2.cedom.gob.ar/es/ legislacion/normas/leyes/ley5704.html

L’Huillier, F. \& Ouvińa, H. (2016). Del indoamericano a la carpa villera. Derecho a la ciudad y luchas por la urbanización de las villas (2010-2016). Quid 16(6), 54-87. https:// publicaciones.sociales.uba.ar/index.php/quid16/article/view/2082

LPO (La Política Online). (2016, septiembre 1). https://www.lapoliticaonline.com/nota/99995la-ciudad-construira-un-parque-olimpico-en-soldati-que-podria-albergar-al-nuevocenard/

Menazzi, L. (2018). "Un nuevo paisaje urbano". La producción de espacios verdes públicos durante la última dictadura cívico-militar en Buenos Aires. Clepsidra. Revista Interdisciplinaria de Estudios sobre Memoria, 5(9), 14-33. http://ppct.caicyt.gov.ar/ index.php/clepsidra/article/view/MENAZZI

Ministerio de Desarrollo Económico (MDE), Argentina (2013). Programa General de Acción y Plan de Inversiones Años 2013/2015. Buenos Aires: Gobierno de la Ciudad de Buenos Aires (GCBA). 
Noticias Urbanas (CABA, 2016, mayo 19). Se aprobó la concesión del Centro de Exposiciones. Por Redacción NU. http://www.noticiasurbanas.com.ar/noticias/se-aprobo-la-concesiondel-centro-de-concesiones/

Palombi, A. (2013). El conflicto de Villa Cartón. Notas para repensar las políticas de hábitat en la Ciudad Autónoma de Buenos Aires. Acta Académica. X Jornadas de Sociología, 1 al 7 de julio de 2013, Facultad de Ciencias Sociales (FCS), Universidad de Buenos Aires (UBA). http://cdsa.aacademica.org/000-038/76.pdf

Pírez, P. (2016). Buenos Aires: La orientación neoliberal de la urbanización metropolitana. Sociologias, 18(42), 90-118. http://dx.doi.org/10.1590/15174522-018004204

Privitera Sixto, M. R. (2018). Juventud y Derecho a la Ciudad en la comuna "olímpica" (Ciudad de Buenos Aires, 2011-2017). Quid 16,9, 121-138. https://publicaciones. sociales.uba.ar/index.php/quid16/article/view/2891

Ricoeur, P. (1989 [1984]). La vida: un relato en busca de un narrador. En Educación y politica (pp. 52-56). Buenos Aires: Docencia.

Rockwell, E. (2009). Reflexiones sobre el trabajo etnográfico. En La experiencia etnográfica. Historia y cultura en los procesos educativos (pp. 41-96). Buenos Aires: Paidós.

Rodríguez, F., Rodríguez, M. C., \& Huerta, C. (coords.) (2013). Diagnóstico socio-habitacional de la Ciudad de Buenos Aires. Buenos Aires: Consejo Económico y Social de la Ciudad Autónoma de Buenos Aires. httm://bdigital.cesba.gob.ar/handle/123456789/71

Sarmiento, I. (2011). Política habitacional en la mira. Intervenciones estatales tras el incendio de Villa Cartón. Percepciones de los habitantes del centro de evacuados Parque Roca. IX Jornadas de Sociología. FCS, UBA.

Secretaría de Hábitat e Inclusión (seCHI). (2015). Proyecto Urbano Integral. Un nuevo modelo de gestión pública. Buenos Aires: Gobierno de la Ciudad de Buenos Aires / Secretaría de Hábitat e Inclusión. https://vdocuments.mx/proyecto-urbano-integral-puico.html

Socoloff, I. (2017). Una reflexión sobre los distritos creativos y las mutaciones del empresarialismo urbano porteño. Quid 16(7), 1-6. https://publicaciones.sociales.uba. ar/index.php/quid16/article/view/2843

Tavella, G. (2018). Interama: el parque de diversiones para la ciudad de Buenos Aires de la dictadura militar (1976-1983). Clepsidra. Revista Interdisciplinaria de Estudios sobre Memoria, 5(9), 34-51. http://ppct.caicyt.gov.ar/index.php/clepsidra/article/view/ TAVELLA

Theodore, N., Peck J., \& Brenner, N. (2009). Urbanismo neoliberal: la ciudad y el imperio de los mercados. Temas Sociales 66. Santiago de Chile: Ediciones SUR. http://www. sitiosur.cl/r.php?id=898

Urgente24 (2017, 16 de marzo). Inauguran terminal Dellepiane pero dicen que no está en condiciones. Por Urgente 24. https://archivo.urgente24.com/262913-inauguranterminal-dellepiane-pero-dicen-que-no-esta-en-condiciones

Vainer, C. (2011). Cidade da exceção: reflexões a partir do Rio de Janeiro. Anais do xiv Enanpur (Encontro Nacional da Associação Nacional de Pós-Graduação e Pesquisa em Planejamento Urbano e Regional). Rio de Janeiro, 23 a 27 de maio de 2011, Associaçáo Nacional de Pós-Graduação e Pesquisa em Planejamento Urbano e Regional (ANPUR). http:// pfdc.pgr.mpf.mp.br/atuacao-e-conteudos-de-apoio/publicacoes/direito-a-moradiaadequada/artigos/cidade-de-excecao-carlos-vainer 
Zapata, M.C. (2013). Toma de tierras en la ciudad de Buenos Aires: Un análisis de las causas estructurales que anunciaron el conflicto del Parque Indoamericano. Pampa (Santa $\mathrm{Fe}$ ), (9), 45-71. http://www.scielo.org.ar/scielo.php?script=sci_arttext\&pid=S231402082013000100003\&lng=es\&tlng=es 